\title{
Cloning, expression and characterisation of a cysteine protease from Trichinella spiralis
}

\author{
Yan Yan Song*, Li Ang Wang*, Hua Na Ren, Xin Qi, Ge Ge Sun, Ruo Dan Liu, Peng Jiang, Xi Zhang, Jing Cui \\ and Zhong Quan Wang
}

Department of Parasitology, Medical College, Zhengzhou University, PR China

${ }^{*}$ These authors contributed on the work equally.

\begin{abstract}
Cysteine protease is a superfamily of widespread proteolytic enzymes and plays a major role in larval invasion, migration, exsheathing, survival and immune evasion in parasites. In the present study, the gene coding cysteine proteinase of the nematode Trichinella spiralis (Owen, 1835) was cloned into pQE-80L and subsequently expressed in E. coli JM109. The rTsCP was purified and its antigenicity was identified by Western blot and ELISA. Using anti-rTsCP serum the native TsCP was identified in muscle larval crude proteins. The results of quantitative real-time PCR and immunofluorescence test demonstrated that the TsCP was expressed in all stages of T. spiralis and located mainly in cuticle, stichosome and reproductive organs. The immunisation of mice with $\mathrm{rTsCP}$ elicited Th2-predominant immune responses. Anti-rTsCP antibodies could partially inhibit the in vitro larval invasion of intestinal epithelial cells and kill the newborn larvae by an antibody-dependent cell-mediated dose-dependent cytotoxicity. The vaccinated mice exhibited a $54 \%$ reduction of adults and a $33 \%$ reduction of muscle larvae following challenge infection. The results suggested that the TsCP might be an indispensable protein in Trichinella invasion, development and survival of T. spiralis in hosts, and could be a potential vaccine target against infection.
\end{abstract}

Keywords: Trichinellosis, cysteine protease, invasion, development

This article contains supporting information (S1) online at http://folia.paru.cas.cz/suppl/2018-65-007.pdf

The adults and larvae of the nematode Trichinella spiralis (Owen, 1835) parasitise the small intestine and skeletal muscle respectively of the same host. The life-cycle is completed within an individual host (Cui et al. 2011). After contaminated meat is ingested by a host, the muscle larvae (ML) are released in the stomach with the aid of digestive enzymes, migrate to the small intestine, and develop into the intestinal infective larvae (IIL). The IIL penetrate the intestinal epithelium, molt four times and develop into adult worms (AW), which mate and produce newborn larvae (NBL). The NBL invade, mature and encapsulate in skeletal muscles, to complete the life-cycle (Despommier 1983).

However, the mechanism of larval invasion of intestinal epithelium with $T$. spiralis is unclear. Since the larvae do not have oral appendages or spikes, the larval invasion of intestinal epithelial cells (IECs) might not be a simple mechanical penetration (Bruce 1970). But may possibly be mediated by the larval surface or oral secretory proteases (Liu et al. 2015a, 2016). Previous studies showed that when $T$. spiralis IIL were added onto the IEC monolayer, the larvae penetrated the monolayer and produced several proteases which entered into the IECs. (Wang et al. 2012, 2013a). These proteases might interact with the IECs and could play an important role during the larval invasion of IECs, and they could be regarded as potential candidate targets for anti-Trichinella vaccine.

Cysteine protease (CP) is a superfamily of proteolytic enzymes widespread in parasites and plays a major role in their life cycle, including invasion, migration, exsheathing and immune evasion (Chung et al. 1995, Trap and Boireau 2000, Chen et al. 2014, Liu et al. 2015b). The cysteine protease contains cathepsin B, C, F, H, K, L, O, S, V, W and $\mathrm{X}$ (McKerrow et al. 2006). The domain of T. spiralis cysteine protease ( $\mathrm{TsCP}$ ) expressed in this study belongs to peptidase C1A cathepsin B. The host's intestinal mucosa is the first natural barrier for parasite invasion and previous studies showed that the cysteine protease plays important roles in the process of digesting the host's tissue and larval invasion (Chen et al. 2014, Liu et al. 2015b).

To investigate the role of TsCP during the invasion of intestinal mucosa, the conserved domain of $T$. spiralis gut-specific CP was cloned and expressed in the present study. The biological characteristics of the TsCP were iden- 
tified and the partial immune protection elicited by immunisation with the rTsCP was evaluated in a mouse model. The TsCP gene (GenBank accession No. XP_003377082.1) was acquired from draft genome of T. spiralis (see Mitreva et al. 2011).

\section{MATERIALS AND METHODS}

\section{Ethics Statement}

This research was conducted according to the National Guidelines for Experimental Animal Welfare (Minister of Science and Technology of People's Republic of China 2006). All of the animal experiments were authorised by the Zhengzhou University Life Science Ethics Committee (no. 2011-016).

\section{Parasite and mice}

The isolate ISS534 of Trichinella spiralis was collected originally from domestic pigs in Henan Province of China. It was passaged in Kunming mice every $6-8$ months in our laboratory. Female BALB/c mice, specific pathogen-free and 4-6 weeks old, were obtained from the Henan Provincial Experimental Animal Center (Zhengzhou, China).

Collection of parasites and preparation of the antigens of muscle larvae (ML)

The ML were collected by digestion of infected mouse carcasses at 42 days post-infection (dpi) with digestion solution of $0.33 \%$ pepsin ( $1: 31,000$ US National Formulary; Sigma-Aldrich Co., St. Louis, Missouri, USA) and $1 \% \mathrm{HCl}$ (Li et al. 2010). The IIL were recovered from the small intestine of infected mice at $2 \mathrm{~h}$ post-infection (hpi) (Liu et al. 2015a). AW were collected individually from intestine at 3 dpi and 6 dpi (Sun et al. 2015). The NBL were obtained from female worms incubated in RPMI1,640 medium containing 5,000 worms $/ \mathrm{ml}$ medium and $10 \%$ fetal bovine serum (FBS; Gibco, Langley, Oklahoma, USA) in 5\% $\mathrm{CO}_{2}$ at $37^{\circ} \mathrm{C}$ for $48 \mathrm{~h}$. The excretory-secretory (ES) antigens and crude antigens of ML were prepared as described by Wang et al. (2013b) and Wu et al. (2016).

Expression and identification of cysteine protease of T. spiralis

The full-length sequence of TsCP is 517 amino acids (aa) (1,554 bp). The 280-517 aa (838-1,554 bp) of TsCP was expressed in the present study. The conserved domain (717 bp) of the TsCP gene was amplified by nested PCR with specific primers carrying BamHI and Pst I restriction enzyme sites (bolded) (5'-TCGGATCCTTACCAAAGCATTTTGA-3', 5'-TTCTGCAGTCACAAAGTAAGGCGCAATTTTG-3'). The PCR product was purified and cloned into the prokaryotic expression vector pQE-80L with His-tag (Novagen, La Jolla, CA, USA) (Li et al. 2015). After being identified by digestion with the corresponding restriction enzymes and confirmed by DNA sequencing, the recombinant plasmid (pQE-80L/TsCP) was transformed into Escherichia coli JM109 (Novagen), and the recombinant TsCP was expressed after being induced with IPTG at $30^{\circ} \mathrm{C}$ for $4 \mathrm{~h}$ (Liu et al. 2017). The rTsCP protein was purified by Ni-NTA-Sefinose resin (Sangon Biotech Co., Shanghai, China), and identified by SDS-PAGE (Wang et al. 2013b).

The tertiary structure of deduced protein sequences of $\mathrm{TsCP}$ was analysed using Expasy website (http://web.expasy.org/). The domain structure of TsCP and enzymatic active sites were predicted with a multiple protein alignment constructed with Clustal Omega (Goujon et al. 2010).

\section{Immunisation of mice and determination of anti-rTsCP antibodies}

$\mathrm{BALB} / \mathrm{c}$ mice were randomly divided into three groups of 20 animals per group. The vaccination group was inoculated subcutaneously with $20 \mu \mathrm{g}$ of the rTsCP emulsified with complete Freund's adjuvant, and boosted 3 times by the rTsCP with incomplete Freund's adjuvant at 10 days intervals. Both control groups were inoculated with adjuvant or PBS using the above-mentioned inoculation procedure (Cui et al. 2013). Tail blood from all inoculated mice was collected at $0,10,20,30$, and 40 days after inoculation.

Anti-TsCP total IgG and subtypes (IgG1 and IgG2a) in serum samples of vaccinated mice were investigated by ELISA (Liu et al. 2015c). The plates were coated with $1 \mu \mathrm{g} / \mathrm{ml}$ the rTsCP at $4{ }^{\circ} \mathrm{C}$ overnight, subsequently blocked with Tris-Buffered Saline with Tween-20 (TBST) containing 5\% skimmed milk. Immune serum diluted at $1: 100$ were added and incubated at $37^{\circ} \mathrm{C}$ for $1 \mathrm{~h}$. HRP-conjugated anti-mouse antibodies IgG, IgG1 and IgG2a (1 : 5,000; Sigma-Aldrich Co.) were added as the secondary antibodies, and o-phenylenediamine dihydrochloride (Sigma-Aldrich Co.) was used as a substrate. The absorbance at $490 \mathrm{~nm}$ was measured with a microplate reader (Tecan, Schweiz, AG, Switzerland).

\section{Challenge infection}

Each group of mice was challenged orally with $300 \mathrm{~T}$. spiralis ML at 10 days after the last vaccination. At day 5 after challenge, 10 mice from each group were killed and the AW were collected from the small intestine (Yang et al. 2010). The remaining 10 mice of each group were killed at day 35 after challenge, and the carcasses weighed and digested ( $\mathrm{Li}$ et al. 2010). The ML of each mouse were examined and counted. The worm reduction rates in AW and ML were evaluated based on the recovered intestinal AW and larvae per gram (LPG) muscle from the vaccinated mice with rTsCP compared with those from the PBS control mice $(\mathrm{Gu}$ et al. 2017).

\section{Analysis of rTsCP antigenicity}

About $13 \mu \mathrm{g} /$ lane of rTsCP, ML crude and ES antigens were separated with SDS-PAGE ( $\mathrm{Li}$ et al. 2015). After blotting, the membranes were blocked by $5 \%$ skimmed milk in TBST $(\mathrm{pH}$ 7.4) at $37^{\circ} \mathrm{C}$ for $1 \mathrm{~h}$, and incubated with different mouse serum ( 1 : 100 dilution) at $37^{\circ} \mathrm{C}$ for $1 \mathrm{~h}$. The blots were washed and incubated at $37^{\circ} \mathrm{C}$ for $1 \mathrm{~h}$ with HRP-conjugated goat anti-mouse IgG (1 : 5,000 dilution; Sigma-Aldrich Co.). Finally, the blots were visualised with 3, 3'-diaminobenzidine tetrahydrochloride (DAB; Sigma-Aldrich Co.) (Wang et al. 2017a).

\section{Analysis of transcriptional level of TsCP gene in various stages of $T$. spiralis}

The worms of various stages of $T$. spiralis (AW at 3 and $6 \mathrm{dpi}$, NBL, ML and IIL) were collected from infected mice and total RNA was isolated with Trizon reagent (Invitrogen, Carlsbad, CA, USA). The transcriptional level of TsCP gene in T. spiralis at various stages was determined by the quantitative real-time 
PCR (qPCR) with an ABI 7500 fast real-time PCR system (Applied Biosystems, MD, USA). The primers of the TsCP gene were 5'-GCAGCTATGGATGTTCAGGTG-3', and 5'-TACGGCTGACAGCATGATTTG-3'. Trichinella spiralis glyceraldehyde-3-phosphate dehydrogenase (GAPDH, GenBank accession No. AF452239) was used as internal control, and the data were calculated using the comparative $\mathrm{Ct}\left(2^{-\Delta \Delta \mathrm{Ct}}\right)$ method (Liu et al. 2013).

\section{Immunofluorescence test (IFT)}

The immunolocalisation of the native TsCP at different stages of $T$. spiralis were examined by IFT (Cui et al. 2015a). The ML, IIL and AW were fixed with $4 \%$ paraformaldehyde, embedded in paraffin and cut into $3-\mu \mathrm{m}$-thick sections. The sections were deparaffinised in xylene and subsequently rehydrated in different dilutions of ethanol. The intact worms and their sections were blocked with $5 \%$ normal goat serum at $37^{\circ} \mathrm{C}$ for $1 \mathrm{~h}$ and incubated at $4{ }^{\circ} \mathrm{C}$ overnight with a $1: 10$ dilution of anti-TsCP mouse serum, mouse infection serum or serum from pre-immune mice. After being washed, sections were incubated with FITC-labeled goat anti-mouse IgG (1 : 100 dilution; Santa Cruz Biotechnology, Dallas, Texas, USA), and examined under a fluorescence microscope (Olympus, Tokyo, Japan) (Li et al. 2015).

\section{The in vitro invasion assay}

IECs were collected from fetal mouse intestines and cultured in Dulbecco's modified Eagle's medium (DMEM; Gibco) (Ren et al. 2011, Long et al. 2015). The ML were activated by mouse bile $(1: 20)$ in $5 \% \mathrm{CO}_{2}$ at $37^{\circ} \mathrm{C}$ for $2 \mathrm{~h}$, and the bile was removed by washing the larvae with PBS (Gagliardo et al. 2002). The IECs were grown to confluence in six-well culture plates. The number of larvae used in this assay was 144-150. The larvae were suspended in semisolid medium (serum-free DMEM with $15 \mathrm{mM}$ HEPES and $1.75 \%$ agarose) and added to the cell monolayer. The medium contained anti-rTsCP serum $(1: 100$ to $1: 1,600$ dilution), infection serum or pre-immune serum (1:100 dilution) (ManWarren et al. 1997). The larvae invading the monolayer were observed and counted under an inverted phase-contrast microscope (Olympus). The larvae penetrating and migrating in the monolayer were counted as invaded larvae, whereas the larvae that were still suspended in medium was regarded as non-invaded larvae (Wang et al. 2013b, Cui et al. 2015b).

\section{Antibody-dependent cell-mediated cytotoxicity (ADCC) test}

The cytotoxicity of anti-rTsCP antibodies to T. spiralis NBL was measured (Moskwa 1999, Liu et al. 2015b). The assay was performed in a 96-well culture plate. A total of $200 \mu$ suspension containing approximately $50 \mathrm{NBL}$ and $2 \times 10^{5}$ peritoneal macrophages (MPMs) from normal mice was placed in each well. Anti-rTsNd serum was diluted at $1: 5$ to $1: 1,000$ in RPMI 1,640 media. Positive control was performed with serum of T. spiralis-infected mice and negative control was conducted with pre-immune serum from normal mice in the presence of MPMs. The plates were kept in an atmosphere of $5 \% \mathrm{CO}_{2}$ at $37^{\circ} \mathrm{C}$ for $24 \mathrm{~h}$. The morphology and activity of NBL was observed under microscope. The viable NBL were active and exhibited wriggling motion, whereas the dead NBL were straight, immobile or disintegrated (Veerapathran et al. 2009, Cui et al. 2015b). The percent-

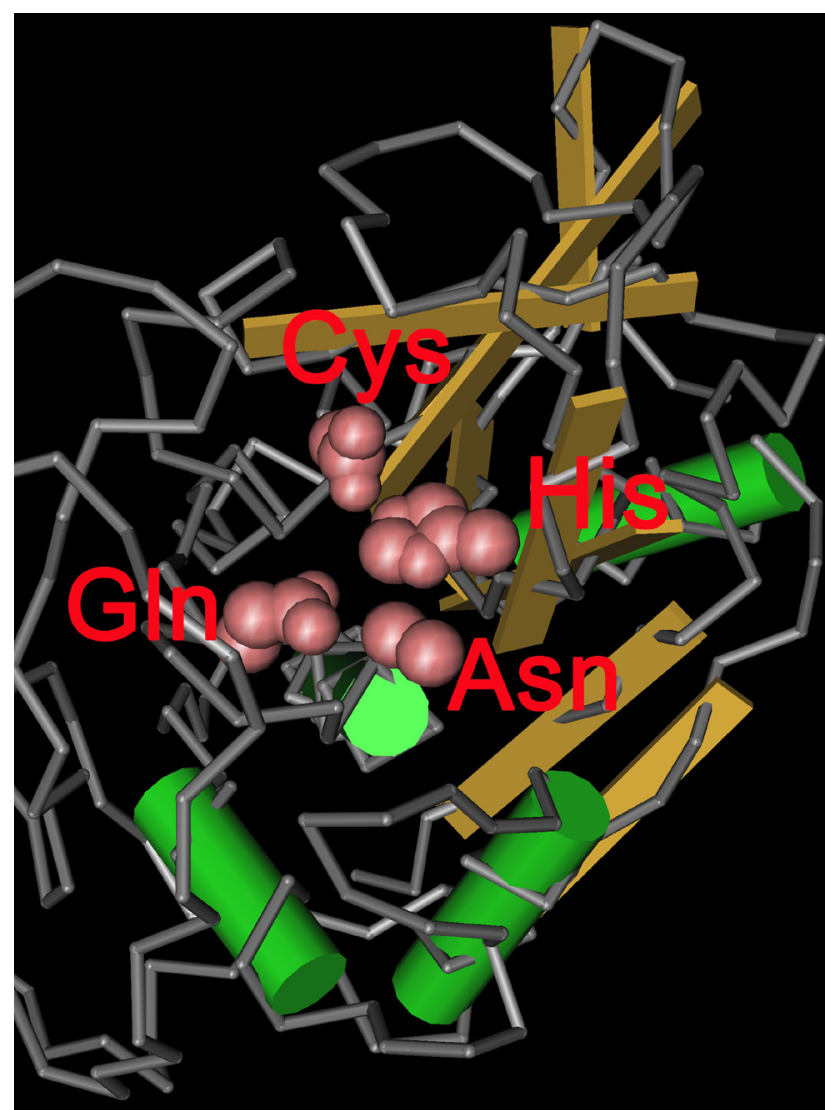

Fig. 1. Predicted three-dimensional structure of Trichinella spiralis (Owen, 1835) cysteine proteinase (TsCP). The active site of TsCP is represented by the yellow sphere and the catalytic residues are Cys308, His459, Gln302 and Asn479.

age cytotoxicity was expressed as the ratio of dead NBL to the total number of the NBL collected from each experiment.

\section{Statistical analysis}

Data were analysed using IBM SPSS statistics analysis software Statistics 22, and shown as the mean value \pm standard deviation. One-way ANOVA was used to compare the differences among the groups. Differences were regarded as statistically significant at $P<0.05$.

\section{RESULTS}

\section{Expression and identification of recombinant cysteine proteinase protein of Trichinella spiralis (TsCP)}

The full-length sequence of $T$. spiralis $\mathrm{TsCP}$ gene is $1,554 \mathrm{bp}$. The conserved domain (838-1,554 bp) of the TsCP was cloned and expressed in the present study. The $\mathrm{CN} 3 \mathrm{D}$ predicts that the TsCP protein belongs to the peptidase $\mathrm{C} 1 \mathrm{~A}$ cathepsin $\mathrm{B}$ and has a structural domain of 302-344 aa and 459-479 aa. The catalytic residues of the cathepsin B are Cys308 and His459, but there are two other residues that may play an important role in the catalysis, a Gln302, before catalysing Cys308, contributes to the formation of oxyanions and an Asn479 residue which orients the imidazolium ring of the catalytic His459 (Fig. 1).

The analysis of DNA sequences showed that the amplified fragment of the TsCP gene cloned in the present study 


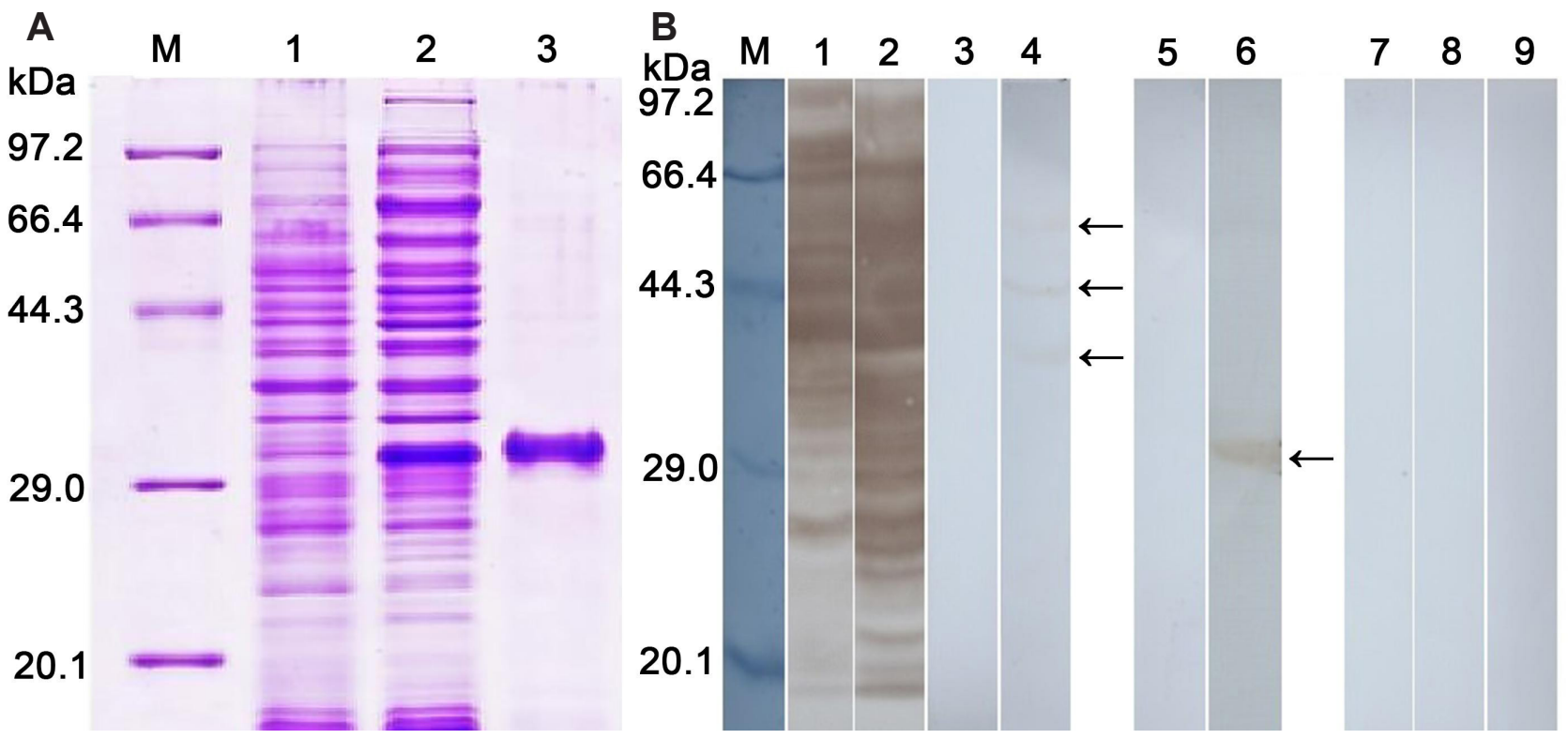

Fig. 2. Identification of rTsCP. A - The SDS-PAGE analysis of rTsCP. The protein molecular weight marker (M); recombinant bacteria lysate before induction (lane 1) and after induction (lane 2); the purified rTsCP (lane 3); B - Western blot analysis of rTsCP. Muscle larvae (ML) of Trichinella spiralis (Owen, 1835) crude (lane 1) and excretory-secretory (ES) antigens (lane 2) were probed with serum of T. spiralis-infected mice, but the rTsCP (lane 3) could be not probed with infection serum. The arrows indicate that the native cysteine proteinase of Trichinella spiralis (TsCP) in ML crude antigens (lane 4) and $\mathrm{rTsCP}$ (lane 6) were probed with mouse anti-rTsCP antibodies, but the ML ES antigens (lane 5) were not probed with anti-rTsCP antibodies. The ML crude (lane 7), ES antigens (lane 8) as well as rTsCP (lane 9) could be not probed with pre-immune serum.

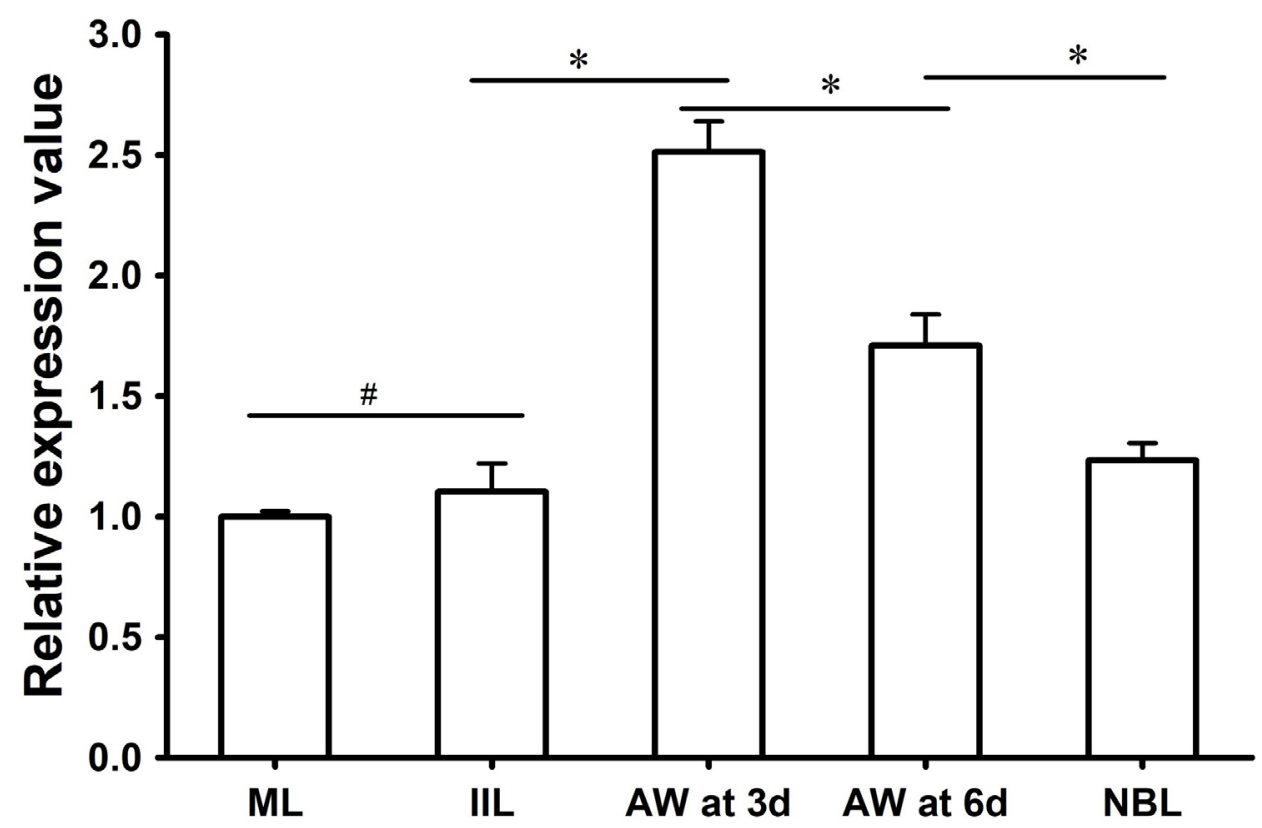

Fig. 3. Quantitative real-time PCR (qPCR) analysis of transcription levels of the cysteine proteinase of Trichinella spiralis (TsCP) in various life cycle stages of Trichinella spiralis (Owen, 1835). The transcription level of TsCP in AW at 3 and 6 days post-infection, muscle larvae (ML), intestinal infective larvae (IIL) and newborn larvae were analysed using the $\mathrm{Ct}\left(2^{-\Delta \Delta C T}\right)$ ratio, with glyceraldehyde-3-phosphate dehydrogenase as an internal control. The transcription level of TsCP in AW stage was significantly higher than those in all of the larval stages. Asterisk indicates significant differences $(P<0.05)$; hashtag $\mathrm{P}>0.05$ compared between the ML and IIL stages.

was $717 \mathrm{bp}$ and was $100 \%$ identical to the sequence of the TsCP gene (GenBank accession no. XP_003377082.1). The TsCP gene was successfully cloned into prokaryotic expression vector $\mathrm{pQE}-80 \mathrm{~L}$. The recombinant TsCP was expressed in E. coli JM109 under induction with $0.1 \mathrm{mM}$
IPTG at $30^{\circ} \mathrm{C}$ for $4 \mathrm{~h}$. On SDS-PAGE analysis, the purified rTsCP protein had a molecular weight (MW) size of $31 \mathrm{kDa}$ and was compatible with its predicted size (Fig. $2 \mathrm{~A})$. The purified rTsCP could be probed by anti-rTsCP serum. Using anti-rTsCP serum several native TsCP proteins 


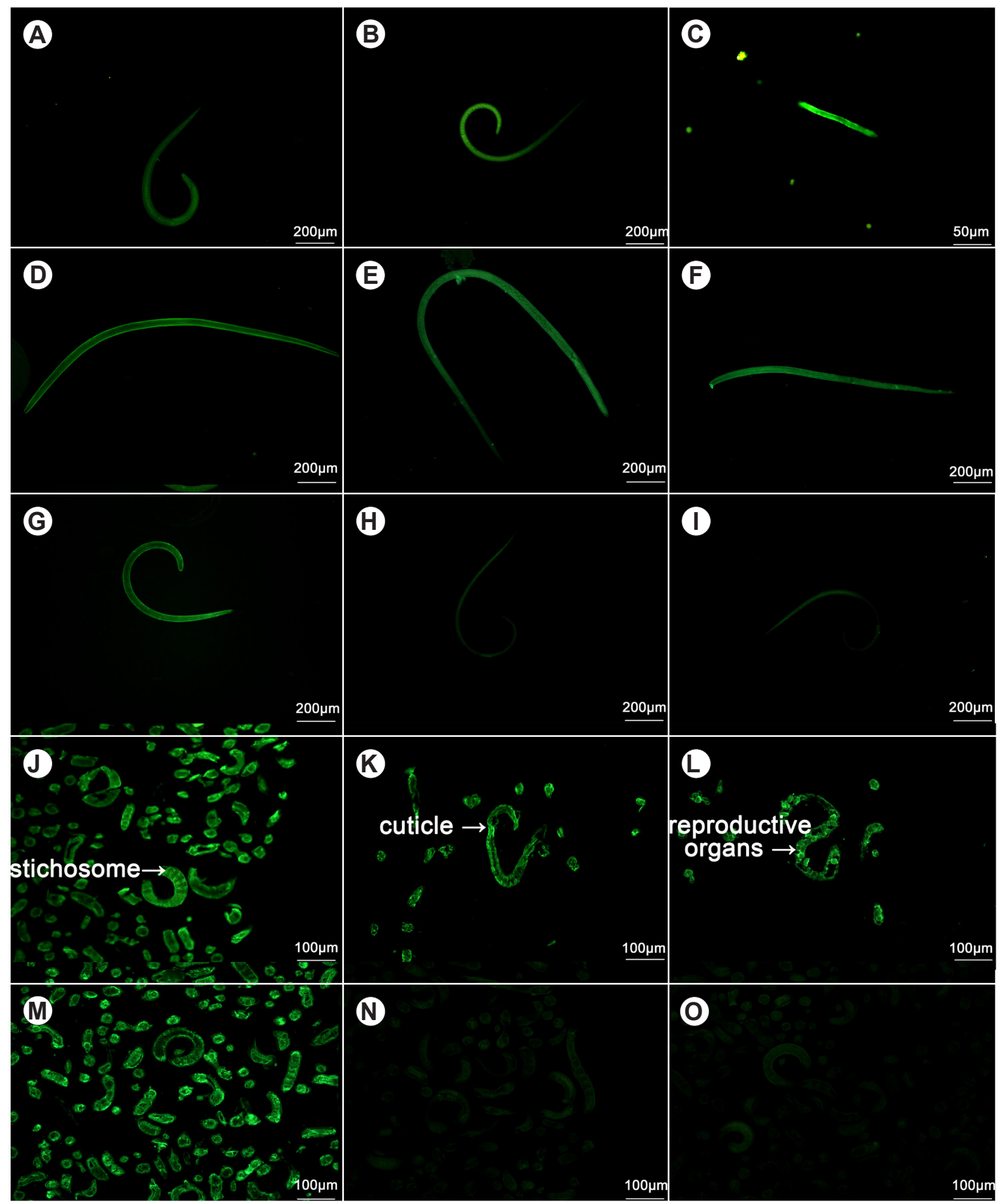

Fig. 4. Expression and immunolocalisation of cysteine proteinase of Trichinella spiralis (TsCP). $\mathbf{A}-\mathbf{F}$ - intact worms of various stages of Trichinella spiralis (Owen, 1835) positively reacted with anti-rTsCP serum. Infection serum (G) were applied as positive control and pre-immune serum (H) and PBS (I) were applied as negative control. A, G-I - muscle larvae at 42 days post-infection (dpi); $\mathbf{B}$ - intestinal infective larvae at 2 hour post-infection (hpi); C - newborn larvae; D - female adult worm at 3 dpi; $\mathbf{E}$ - female adult worm at $6 \mathrm{dpi} ; \mathbf{F}$ - male adult worm at $3 \mathrm{dpi} ; \mathbf{J}, \mathbf{L}$ - the worm sections were positively reacted with anti-rTsCP serum. The fluorescent staining is detected in cuticle and stichosome of muscle larvae at 42 dpi $(\mathbf{J})$ and intestinal infective larvae at 2 hpi (K), and reproductive organs of adult worm at $3 \mathrm{dpi}(\mathbf{L})$. The muscle larvae treated with infection serum $(\mathbf{M})$ were applied as positive control; the muscle larvae treated with pre-immune serum $(\mathbf{N})$ and PBS $(\mathbf{O})$ were applied as negative control. 

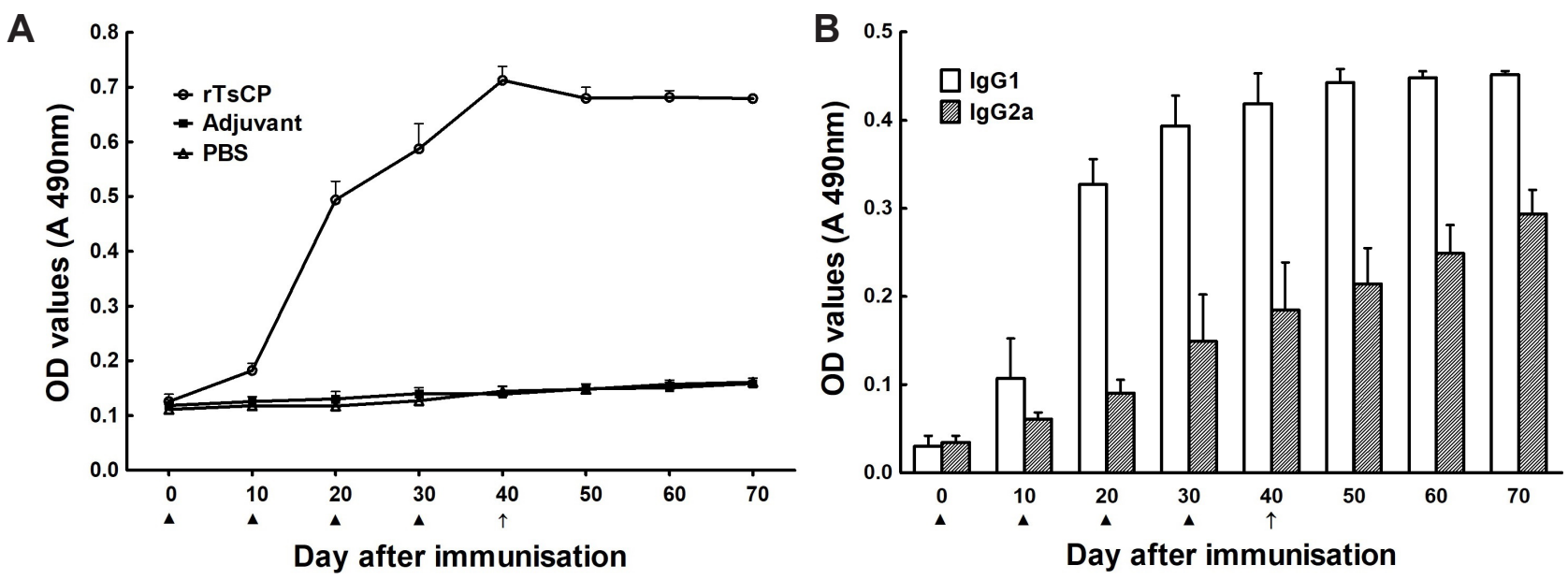

Fig. 5. Detection of antibody responses in mice immunisated with $\mathrm{rTsCP}$. A - mouse serum specific $\operatorname{IgG}$; B - IgG subclass responses to the $\mathrm{rTsCP}$ at different intervals after immunisation were assayed by ELISA. The values are shown as the mean optical density (OD) values of ten mice \pm SD of the antibody levels. The vaccination time points are marked with solid triangles $(\boldsymbol{\Delta})$ and the challenge infection time is marked with an arrow $(\uparrow)$.

A

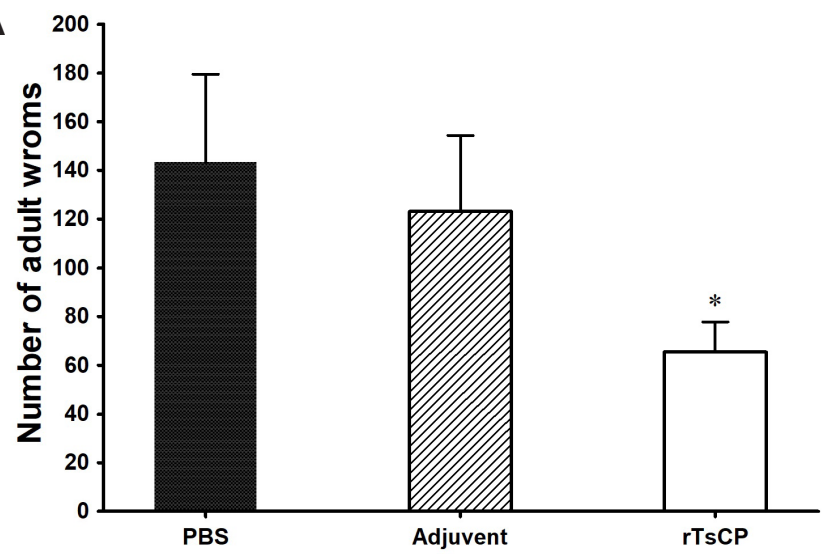

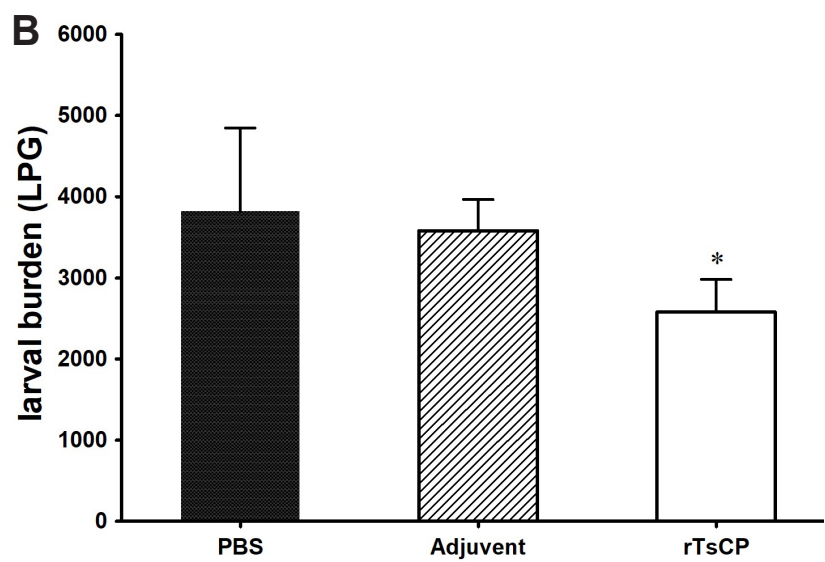

Fig. 6. A - Intestinal adult worms; B - larvae per gram (LPG) of muscles of immunised mice after a challenge with 300 Trichinella spiralis (Owen, 1835) muscle larvae. The results are presented as the mean of 12 mice per group \pm SD. Asterisks indicate statistically significant differences $(P<0.05)$ in worm burdens of the immunised group or compared to adjuvant only group and PBS control group.

(38.4, 44.6 and $57.9 \mathrm{kDa})$ were identified in T. spiralis ML crude antigens, but no native TsCP was observed in ML ES antigens (Fig. 2B).

\section{Transcription level of TsCP in various stages}

Transcription level of TsCP was detected by qPCR in the various life-cycle stages of $T$. spiralis. It revealed the TsCP gene was transcribed at all stages (AW at 3 and 6 dpi, NBL, ML and IIL) (Fig. 3). The TsCP transcription level was highest in AW stage at 3 dpi and was higher in AW than in the larval stages $(P<0.05)$. It further demonstrated that the TsCP was an up-regulated gene in intestinal adult stage of $T$. spiralis and gut-specific. The differences between the ML and IIL stages were not statistically significant $(P>0.05)$.

\section{Expression and immunolocalisation of TsCP at various stages}

In the immunolocalisation assay, the fluorescent staining using anti-rTsCP serum was observed at all developmental stages of T. spiralis (AW, NBL, ML and IIL) (Fig. 4). Additionally, intense fluorescent staining was found in the anterior end of the IIL at 2 hpi during molting (Fig. S1). When the sectioned worms were treated with anti-rTsCP serum, positive staining was observed in the cuticle, stichosome and reproductive organs of AW, ML and IIL. No fluorescence was be detected in ML incubated with pre-immune serum.

\section{Humoral responses triggered by vaccination with $\mathbf{r T s C P}$}

Serum specific anti-rTsCP IgG titres of vaccinated mice were determined by ELISA 7 days after the third vaccination, the mean $\operatorname{IgG}$ titre of ten mice reached $1: 100,000$. Anti-rTsCP IgG levels were remarkably elevated after the second and third immunisation and peaked 10 days after the fourth immunisation. In contrast anti-rTsCP antibody levels did not increase further after challenge. None of the mice inoculated with adjuvant or PBS exhibited obvious detectable anti-rTsCP antibodies (Fig. 5A). Anti-rTsCP IgG subclass assay showed that the levels of $\operatorname{IgG1}$ on days 10 , 




Fig. 7. The in vitro inhibition of invasion of intestinal epithelial cell IEC monolayer with larvae of Trichinella spiralis (Owen, 1835) by anti-TsCP serum with different dilutions. Mouse infection serum (IS, $1: 100$ ) and pre-immune serum (PI, $1: 100)$ were used as positive and negative controls, respectively. The results are presented as the percentages of the larvae invading the IEC monolayer and are shown as the mean \pm SD of three independent experiments. Asterisks indicate statistically significant differences $(P<0.001)$ compared with pre-immune serum group.

20,30 and 40 after vaccination were higher than those of IgG2a $\left(\mathrm{t}_{10 \mathrm{~d}}=3.398, \mathrm{t}_{20 \mathrm{~d}}=24.142, \mathrm{t}_{30 \mathrm{~d}}=9.240, \mathrm{t}_{40 \mathrm{~d}}=8.616\right.$, $P<0.05$ ) (Fig. 5B), indicating that the predominant IgG subclass elicited with rTsCP was IgG1. However the $\operatorname{IgG} 2 \mathrm{a}$ antibody response also increased after the immunisation.

\section{Immune protective effects of $\mathrm{rTsCP}$}

Mice vaccinated with $\mathrm{rTs} C \mathrm{P}$ showed a $54 \%$ reduction in AW burden 5 days after challenge and a 33\% reduction in ML burden at day 35 after challenge (Fig. 6), when compared with the PBS control mice $\left(F_{\text {adults }}=49.09, F_{\text {larvae }}=7.602\right.$, $P<0.05)$. In addition, the adult and larval burdens of the immunised group were also significantly lower than those of the adjuvant control mice $(\mathrm{P}<0.05)$.

\section{Inhibition of larval invasion of IECs}

The invasion rate of larvae into IEC monolayer was $40 \%, 17 \%$ and $80 \%$, respectively $\left(\chi^{2}=130.117, P<0.001\right)$, after anti-rTsCP serum, infection serum and pre-immune mouse serum respectively were added to the medium. The inhibition of anti-rTsCP serum on larval invasion of IECs was dose-dependent and showed a decreasing trend with the increase of serum dilution $(F=47.008, P<0.001)$. No inhibition was observed with the pre-immune serum (Fig. 7).

\section{In vitro $\mathrm{ADCC}$ test}

The results of ADCC test revealed that anti-rTsCP serum could accelerate the adherence of the MPMs to the NBL at different times after incubation (Figs. 8, 9), and resulted in the greater deaths of the NBL incubated in $1: 100$ dilution of anti-rTsCP serum for $72 \mathrm{~h}$ (42\% cytotoxicity), when compared with the NBL treated with pre-immune serum $(12 \%$ cytotoxicity; $F=360.045, P<0.05)$. The cytotoxicity of anti-rTsCP serum against NBL was dose-dependent, and showed a decreasing trend with the increase of anti-rTsCP serum dilution $(F=262.572, P<0.05)$. The results revealed that anti-rTsCP serum could prompt cell-mediated cytotoxicity, which could contribute to the protective immunity elicited by the vaccination of mice with rTsCP.

\section{DISCUSSION}

Cysteine protease is a superfamily of proteolytic enzymes widespread in parasitic organisms and contains cathepsin B, C, F, H, K, L, O, S, V, W and X (McKerrow et al. 2006, Qu et al. 2015). Previous studies showed that cysteine protease plays important roles during the life cycle of parasites, including cell and tissue invasion, larval migration, exsheathing/excystment, nutrient uptake and immune evasion (Sajid and McKerrow 2002). The cysteine protease from parasites also has indispensable catabolic functions (such as degrading collagen, fibrinogen, plasminogen, immunoglobulin and hemoglobin), and might be related to digest on host of tissue and facilitating invasion (Chen et al. 2014, Liu et al. 2015b). Therefore, cysteine protease seems to be an essential protein for the penetration, development and survival of the parasites and might be an important potential vaccine target.

Cysteine protease has been detected in the soluble and ES proteins of adult worms and muscle larvae of Trichinella spiralis (see Todorova 2000, Yang et al. 2015). Previous studies showed that when the infective larvae were inoculated onto the IEC monolayer, they penetrated the IECs and generated some additional proteases (e.g. metalloprotease, serine proteases and cysteine proteases) (Wang et al. 2013a). However, the immune protection produced by immunisation with the native or recombinant cysteine protease of $T$. spiralis has been not reported.

In the present study, the conserved domain (838-1,554 bp) of the TsCP gene was successfully expressed in an Escherichia coli JM109. Vaccination with rTsCP triggered strong specific antibodies to rTsCP and elicited Th2-predominant immune responses (high levels of IgG1) in immunised mice. On Western blot analysis, anti-TsCP serum identified the native TsCP in the ML crude proteins, but not in ML ES antigens. Furthermore, the rTsCP was recognised by anti-TsCP serum, but not by 




Fig. 8. Antibody-dependent cell-mediated cytotoxicity (ADCC) test. Newborn larvae (NBL) of Trichinella spiralis (Owen, 1835) recovered from cultures after ADCC test $(\times 200)$. In the test, the NBL were incubated with anti-rTsCP serum, infection, mouse pre-immune serum or $2 \times 10^{5}$ mouse peritoneal macrophages (MPM). A - no MPM adhered to NBL at $6 \mathrm{~h}$ after incubation and the NBL were active; $\mathbf{B}$ - a few MPM adhered to NBL at $12 \mathrm{~h}$ after incubation and the NBL was still lively; $\mathbf{C}$ - numerous MPM adhered to NBL at 72 $\mathrm{h}$ after incubation and the NBL were dead and disintegrated; D - mouse infection serum; $\mathbf{E}$ - mouse pre-immune; F - PBS a adjuvant were applied as a positive and negative control, respectively.

mouse infection serum. The results are similar to those of glutathione-S-transferase (TsGST) of T. spiralis which is a cytoplasmic protein, and not an ES protein (Li et al. 2015). The previous studies also revealed that the native TsCP was observed by immune-histochemical staining in the midgut, stichosome, genital primordium and somatic muscles of $T$. spiralis ML, but the enzyme was not detected in the ES products of T. spiralis ML (Moczon and Wranicz 1999). The results demonstrated that the native TsCP is a cytoplasmic protein, and not ES protein, suggesting that the native cytoplasmic TsCP protein could not enter the host's peripheral blood circulation. The native $\mathrm{TsCP}$ is not in direct contact with the immune system and could not stimulate the host to produce abundant anti-TsCP antibody response during natural infection with species of Trichinella.

Our results indicated that the TsCP could be a component of muscle larval somatic proteins of $T$. spiralis, not ML ES proteins. The calculated theoretical MW of the TsCP domain is about $28.5 \mathrm{kDa}$, but the MW of the TsCP domain expressed in the present study is approximately $31 \mathrm{kDa}$. The reason of the MW difference is unknown. As shown in Fig. 1B, the inconsistence of the MW of the native TsCP (38.4 kDa, 44.6 kDa and $57.9 \mathrm{kDa}$ ) in ML crude antigens of T. spiralis and $\mathrm{rTsCP}(31 \mathrm{kDa})$ is possible because only the conserved domain (717 bp) of the TsCP gene was expressed in our study, not the full-length sequence of TsCP gene (1,554 bp). Alternatively, the sequences of the TsCP gene expressed in this study come from the draft genome of T. spiralis by conceptual translation (Mitreva et al. 2011). So, the TsCP protein might have different isoforms, or this protein could be processed by post-translational modifications and/or alternative splicing (Robinson et al. 2007, Bien et al. 2015, Cui et al. 2015a).

The transcription of the TsCP gene was detected by qPCR at all of life-cycle stages of $T$. spiralis (AW, NBL, ML and IIL), but the transcription level of the TsCP in AW stages at 3 and 6 dpi was obviously higher than those in the larval stages (NBL, ML and IIL), further suggesting that the TsCP was gut-specific up-regulated gene in intestinal adult stage of T. spiralis. The expression of the TsCP was observed by IFT at all stages of $T$. spiralis (AW, NBL, ML and IIL), principally located in cuticle, stichosome and reproductive organs. Previous studies showed that serine proteases, glutathione S-transferase, aminopeptidase and nudix hydrolase were expressed in various stages of $T$. spiralis (see Wang et al. 2013b, Zhang et al. 2013, Long et al. 2015). The excystation of trophozoites of Giardia lamblia (Kunstler, 1882) and metacercariae of Paragonimus westermani (Kerbert, 1878) is blocked or inhibited by specific cysteine protease inhibitors (E-64) in dose-dependent manner, suggesting that cysteine proteases of the parasites are involved in excystment (Chung et al. 1995, 


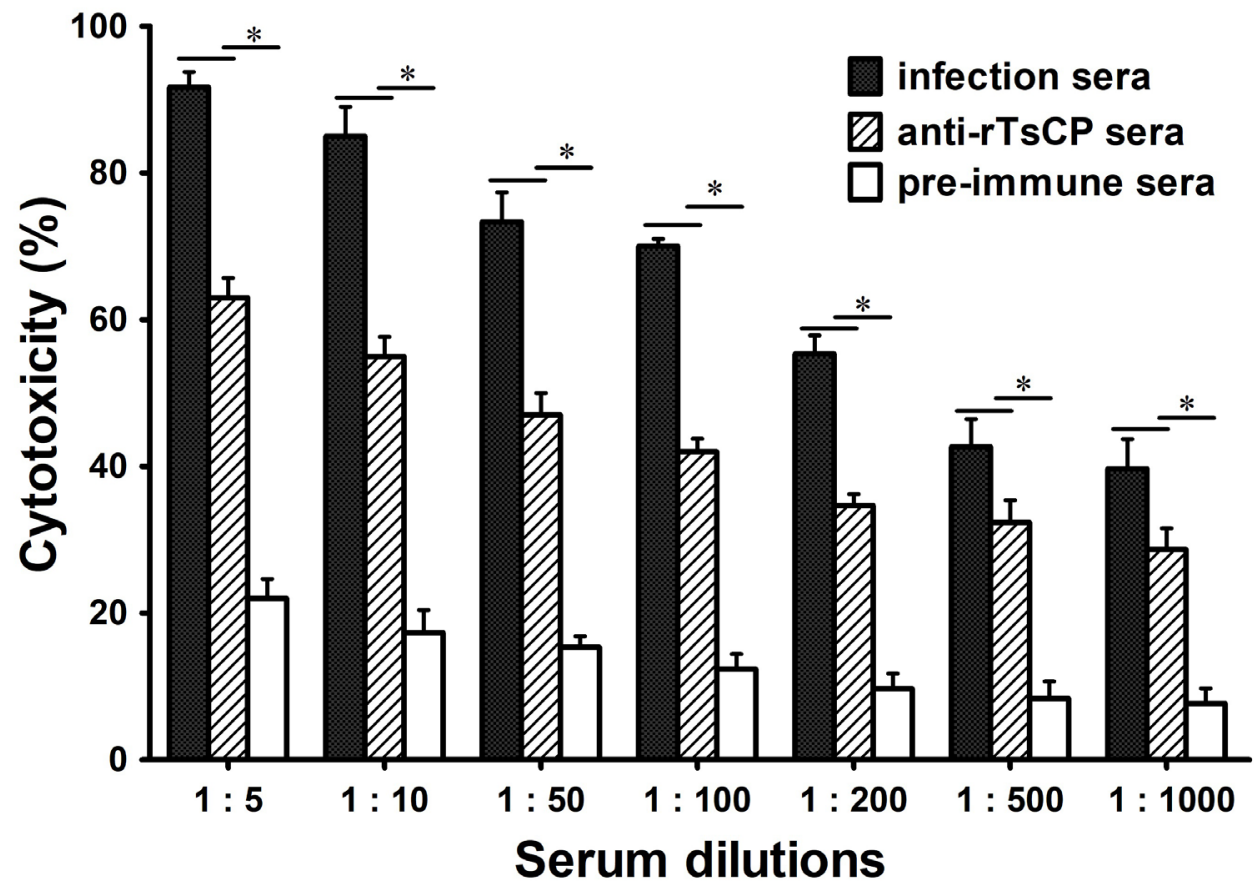

Fig. 9. Antibody-dependent cell-mediated cytotoxicity test. The cytotoxicity of anti-rTsCP antibodies was dose-dependent $(P<0.05)$. Asterisks indicate the cytotoxicity of anti-rTsCP serum and mouse infection serum showed a distinct difference $(P<0.05)$ when compared with that of mouse pre-immune serum.

Ward et al. 1997). The enzymatic activity of cysteine protease was observed in whole worm soluble proteins of the L3 and L4 stage larvae of Dirofilaria immitis (Leidy, 1856). They could degrade glycoprotein, elastin and collagen while the larval molting began (Richer et al. 1992). As shown in Fig. S1, our results also indicated an intense fluorescent staining (yellow) in the anterior end of the IIL at 2 hpi during molting. These results suggest that the TsCP was also involved in exsheathing in this nematode.

In this experiment, the Th2-predominant immune responses have been successfully elicited by vaccination with rTsCP. Vaccinated mice exhibited a 54\% reduction in adult worm burden of intestines at day 5 after challenge and a 33\% reduction in larval burden of muscles at day 35 post infection. The larval and adult burden reduction observed in our study is similar to those from previous studies (Cui et al. 2013, Long et al. 2014, Wang et al. 2017b). Our results were also consistent with previous reports which indicated that Th2-predominant immune responses in vaccinated mice have been shown to be important, of which anti-Trichinella antibodies play an important role in immune protection against infection with $T$. spiralis (see Wang et al. 2013b, Long et al. 2014, Li et al. 2015). The domain of TsCP expressed in this study belongs to peptidase C1A cathepsin B which may play a major role in intracellular proteolysis. It has a basic position for the proteolysis of extracellular matrix and intercellular communication disruption. Cathepsin B of Clonorchis sinensis (Cobbold, 1875 ) can degrade various human proteins (serum albumin, fibronectin, hemoglobin and IgG) and promote cell proliferation, migration and invasion of human hepatocellular carcinoma and cholangiocarcinoma cells (Chen et al. 2015, Ruan et al. 2016). The intraperitoneal inoculation of mice with rCsCP could provide an effective protection against with $C$. sinensis infection (Wu et al. 2017).

Previous studies also showed that cysteine protease from parasites degraded the host's collagen, fibronectin and elastin (Liu et al. 2015b). The protease enzymatic activity was inhibited by anti-Trichinella antibodies IgG from T. spiralis-infected mice (Todorova 2000). The neutralisation of parasite enzymatic activity might have a favourable effect on the host and could block larval invasion, migration and development. The results suggested that the partial protective immunity elicited by vaccination with rTsCP could be due to generation of anti-TsCP antibodies which partly neutralise cysteine protease activity. Anti-Trichinella antibodies could bind to the surface proteins of infective larvae of $T$. spiralis and partially protect the intestinal epithelium from larval invasion (McVay et al. 1998).

In this study, when anti-rTsCP serum and pre-immune serum were added to the medium, the larval invasion rate in IEC monolayer for anti-rTsCP serum group was significantly lower than that of pre-immune serum group, and was dose-dependent, indicating that anti-TsCP antibodies could inhibit the larval invasion. When the T. spiralis NBL were incubated with peritoneal macrophages (or peripheral blood leukocytes) and these antibodies, anti-Trichinella antibodies were capable of inducing NBL death by activation of the effector cells adhering to and destroying NBL as determined by in vitro ADCC assays (Moskwa 1999, Venturiello et al. 2000).

Our results revealed that anti-rTsCP antibodies participated in the death of the T. spiralis NBL and were antibody dose-dependent. Peritoneal macrophages adhered to and damaged the $T$. spiralis NBL in the aid of anti-rTsCP serum. The above-mentioned results further demonstrated that 
TsCP might be an essential protein in all life-cycle stages acting in the invadion, molting and survival of $T$. spiralis, and could be regarded as a promising potential target for vaccine development. However, the immune protection of rTsCP should be further evaluated, and the polyvalent vaccines from various stages of $T$. spiralis should be studied (Pompa-Mera et al. 2014, Gu et al. 2017).

In conclusion, TsCP was expressed at all life-cycle stages of T. spiralis, and located mainly in cuticle, stichosome and reproductive organs of this parasitic nematode. The immunisation with $\mathrm{rTsCP}$ elicited Th2-pre- dominant immune responses and produced a partial immune protection against the challenge in mice. TsCP might be an essential protein for the invasion, development and survival of $T$. spiralis and could be regarded as a potential vaccine target against Trichinella infection, but immune protective effects should be further evaluated in a swine model.

Acknowledgements. This study was supported by grants of the National Natural Science Foundation of China (nos. 81572024, 81471981 and U1704284).

\section{REFERENCES}

Bien J., Cabaj W., Moskwa B. 2015: Proteomic analysis of potential immunoreactive proteins from muscle larvae and adult worms of Trichinella spiralis in experimentally infected pigs. Folia Parasitol. 62: 022

BRUCE R.G. 1970: Structure of the esophagus of the infective juvenile and adult Trichinella spiralis. J. Parasitol. 56: 540-549.

Chen W., Ning D., Wang X., Chen T., Lv X., Sun J., Wu D., Huang Y., Xu J., YU X. 2015: Identification and characterisation of Clonorchis sinensis cathepsin B proteases in the pathogenesis of clonorchiasis. Parasites \& Vectors 8: 647.

Chen W., Wang X., Lv X., Tian Y., Xu Y., Mao Q., Shang M., Li X., Huang Y., Yu X. 2014: Characterisation of the secreted cathepsin B cysteine proteases family of the carcinogenic liver fluke Clonorchis sinensis. Parasitol. Res. 113: 3409-3418.

Chung Y.B., Kong Y., Joo I.J., Cho S.Y., Kang S.Y. 1995: Excystment of Paragonimus westermani metacercariae by endogenous cysteine protease. J. Parasitol. 81: 137-142.

Cui J., Li L.G., Jiang P., Liu R.D., Yang X., Liu L.N., Liu P., ZHANG S.B., WANG Z.Q. 2015a: Biochemical and functional characterisation of the glutathione S-transferase from Trichinella spiralis. Parasitol. Res. 114: 2007-2013.

Cui J., Ren H.J., Liu R.D., Wang L., Zhang Z.F., Wang Z.Q. 2013: Phage-displayed specific polypeptide antigens induce significant protective immunity against Trichinella spiralis infection in BALB/c mice. Vaccine 31: 1171-1178.

Cui J., Wang L., Sun G.G., Liu L.N., Zhang S.B., Liu R.D., ZhANG X., JiANG P., WANG Z.Q. 2015a Characterisation of a Trichinella spiralis $31 \mathrm{kDa}$ protein and its potential application for the serodiagnosis of trichinellosis. Acta Trop. 142: 57-63.

Cui J., Wang Z.Q., Xu B.L. 2011: The epidemiology of human trichinellosis in China during 2004-2009. Acta Trop. 118: 1-5.

Despommier D.D. 1983: Biology. In: W. Campbell (Ed.), Trichinella and Trichinosis. Plenum Press, New York, pp. 75-151

Gagliardo L.F., McVay C.S., Appleton J.A. 2002: Molting, ecdysis, and reproduction of Trichinella spiralis are supported in vitro by intestinal epithelial cells. Infect. Immun. 70: 1853-1859.

Goujon M., McWilliam H., Li W., Valentin F., Squizzato S., PAERN J., Lopez R. 2010: A new bioinformatics analysis tools framework at EMBLEBI. Nucleic Acids Res. 38: W695-W699.

Gu Y., Sun X., Li B., Huang J., Zhan B., Zhu X. 2017: Vaccination with a paramyosin-based multi-epitope vaccine elicits significant protective immunity against Trichinella spiralis infection in mice. Front. Microbiol. 8: 1475

Li F., CUI J., WANG Z.Q., JiAng P. 2010: Sensitivity and optimisation of artificial digestion in the inspection of meat for Trichinella spiralis. Foodborne Pathog. Dis. 7: 879-885.

Li L.G., Wang Z.Q., LiU R.D., Yang X., Liu L.N., Sun G.G., Jiang P., Zhang X., Zhang G.Y., Cui J. 2015: Trichinella spiralis: Low vaccine potential of glutathione $\mathrm{S}$-transferase against infections in mice. Acta Trop. 146: 25-32.

Liu C.Y., Song Y.Y., Ren H.N., Sun G.G, Liu R.D., Jiang P., Long S.R., Zhang X., Wang Z.Q., Cui J. 2017: Cloning and expression of a Trichinella spiralis putative glutathione S-transferase and its elicited protective immunity against challenge infections. Parasit. Vectors, 10: 448.

Liu L.N., Wang Z.Q., Zhang X., Jiang P., Qi X., Liu R.D., Zhang Z.F., Cui J. 2015b: Characterisation of Spirometra erinaceieuropaei plerocercoid cysteine protease and potential application for serodiagnosis of sparganosis. PLoS Negl. Trop. Dis. 9: e0003807.

Liu P., Cui J., Liu R.D., Wang M., Jiang P., Liu L.N., Long S.R., Li L.G., Zhang S.B., Wang Z.Q. 2015c: Protective immunity against Trichinella spiralis infection induced by $\mathrm{TsNd}$ vaccine in mice. Parasit. Vectors 8: 185.

Liu R.D., Cui J., Liu X.L., Jiang P., Sun G.G., Zhang X., LoNG S.R., WANG L., WANG Z.Q. 2015a: Comparative proteomic analysis of surface proteins of Trichinella spiralis muscle larvae and intestinal infective larvae. Acta Trop. 150: 79-86.

Liu R.D., Jiang P., Wen H., Duan J.Y., Wang L.A., Li J.F., Liu C.Y., Sun G.G., Wang Z.Q., Cui J. 2016: Screening and characterisation of early diagnostic antigens in excretory-secretory proteins from Trichinella spiralis intestinal infective larvae by immunoproteomics. Parasitol. Res. 115: 615-622.

Liu R.D., Wang Z.Q., Wang L., Long S.R., Ren H.J., Cui J. 2013: Analysis of differentially expressed genes of Trichinella spiralis larvae activated by bile and cultured with intestinal epithelial cells using real-time PCR. Parasitol. Res. 112: 4113-4120.

Long S.R., Wang Z.Q., Jiang P., Liu R.D., Qi X., Liu P., Ren H.J., Shi H.N., Cui J. 2015: Characterisation and functional analysis of Trichinella spiralis nudix hydrolase. Exp. Parasitol. 159: $264-273$

Long S.R., Wang Z.Q., Liu R.D., Liu L.N., Li L.G., Jiang P., Zhang X., Zhang Z.F., Shi H.N., Cui J. 2014: Molecular identification of Trichinella spiralis nudix hydrolase and its induced protective immunity against trichinellosis in BALB/c mice. Parasit. Vectors 7: 600

ManWarren T., Gagliardo L., Geyer J., McVay C., Pearce-Kelling S., Appleton J. 1997: Invasion of intestinal epithelia in vitro by the parasitic nematode Trichinella spiralis. Infect. Immun. 65: 4806-4812.

McKerrow J.H., Caffrey C., Kelly B., Loke P., Sajid M. 2006: Proteases in parasitic diseases. Annu. Rev. Pathol. $1: 497-536$

McVay C.S., Tsung A., Appleton J. 1998. Participation of parasite surface glycoproteins in antibody-mediated protection of epithelial cells against Trichinella spiralis. Infect. Immun. 66: 1941-1945.

Mitreva M., Jasmer D.P., Zarlenga D.S., Wang Z., AbUbucker S., Martin J., Taylor C.M., Yin Y., Fulton L., Minx P., Yang S.P., Warren W.C., Fulton R.S., Bhonagiri V., Zhang X., Hallsworth-Pepin K., Clifton S.W., McCarter J.P., Appleton J., Mardis E.R., Wilson R.K. 2011: The draft genome of the parasitic nematode Trichinella spiralis. Nat. Genet. 43: 228-235. 
Moczoń T., Wranicz M. 1999: Trichinella spiralis: proteinases in the larvae. Parasitol. Res. 85: 47-58.

Moskwa B. 1999. Trichinella spiralis: in vitro cytotoxicity of peritoneal cells against synchronous newborn larvae of different age. Parasitol. Res. 85: 59-63.

Pompa-Mera E.N., Arroyo-Matus P., Ocana-Mondragon A., GonZalez-Bonilla C.R., Yepez-Mulia L. 2014: Protective immunity against enteral stages of Trichinella spiralis elicited in mice by live attenuated Salmonella vaccine that secretes a 30-mer parasite epitope fused to the molecular adjuvant C3d-P28. Res. Vet. Sci. 97: 533-545.

Qu Z.G., Ma X.T., Li W.H., Zhang N.Z., Yue L., Cui J.M., CaI J.P., JiA W.Z., FU B.Q. 2015: Molecular characterisation of a cathepsin F-like protease in Trichinella spiralis. Parasit. Vectors 8: 652.

Ren H.J., Cui J., Wang Z.Q., Liu R.D. 2011: Normal mouse intestinal epithelial cells as a model for the in vitro invasion of Trichinella spiralis infective larvae. PLoS One 6: e27010.

Richer J.K., Sakanari J.A., Frank G.R., Grieve R.B. 1992: Dirofilaria immitis: proteases produced by third- and fourthstage larvae. Exp. Parasitol. 75: 213-222.

Robinson M.W., Greig R., Beattie K.A., Lamont D.J., ConNOLLY B. 2007: Comparative analysis of the excretory-secretory proteome of the muscle larva of Trichinella pseudospiralis and Trichinella spiralis. Int. J. Parasitol. 37: 139-148.

Ruan J., Zheng H., Rong X., Rong X., Zhang J., Fang W. Zhaо P., Luo R. 2016: Over-expression of cathepsin B in hepatocellular carcinomas predicts poor prognosis of $\mathrm{HCC}$ patients. Mol. Cancer 15: 17.

Sajid M., McKerrow J.H. 2002: Cysteine proteases of parasitic organisms. Mol. Biochem. Parasitol. 120: 1-21.

Sun G.G., Wang Z.Q., Liu C.Y., Jiang P., Liu R.D., Wen H., Qi X., WANG L., CUI J. 2015: Early serodiagnosis of trichinellosis by ELISA using excretory-secretory antigens of Trichinella spiralis adult worms. Parasit. Vectors 8: 484.

Todorova V.K. 2000: Proteolytic enzymes secreted by larval stage of the parasitic nematode Trichinella spiralis. Folia Parasitol. 47: $141-145$.

Trap C., Boireau P. 2000: Proteases in helminthic parasites. Vet. Res. 31: 461-471.

Veerapathran A., Dakshinamoorthy G., Gnanasekar M., Reddy M.V., Kalyanasundaram R. 2009: Evaluation of Wuchereria bancrofti GST as a vaccine candidate for lymphatic filariasis. PLos Negl. Trop. Dis. 3: e457.

Venturiello S.M., Malmassari S.L., Costantino S.N., NuÑEz G.G. 2000: Cytotoxicity-blocking antibodies in human chronic trichinellosis. Parasitol. Res. 86: 762-767.
WANG B., WANG Z.Q., Jin J., Ren H.J., LiU L.N., CUi J. 2013b: Cloning, expression and characterisation of a serine protease gene encoding $35.5 \mathrm{kDa}$ proteins from Trichinella spiralis. Exp. Parasitol. 134: 148-154.

Wang L, Sun X., Huang J., Zhan B., Zhu X. 2017b: Heterologous prime-boost vaccination enhances TsPmy's protective immunity against Trichinella spiralis infection in a murine model. Front. Microbiol. 8: 1394.

Wang L., Wang Z.Q., CUi J. 2013a: Proteomic analysis of the changed proteins of Trichinella spiralis infective larvae after co-culture in vitro with intestinal epithelial cells. Vet. Parasitol. 194: $160-163$.

Wang Z.Q., Liu R.D., Sun G.G., Song Y.Y., Jiang P., Zhang X., CUI J. 2017a: Proteomic analysis of Trichinella spiralis adult worm excretory-secretory proteins recognised by serum of early patients with trichinellosis. Front. Microbiol. 8: 986.

Wang Z.Q., Wang L., Cui J. 2012: Proteomic analysis of Trichinella spiralis proteins in intestinal epithelial cells after culture with their larvae by shotgun LC-MS/MS approach. J. Proteomics 75: 2375-2383.

Ward W., Alvarado L., Rawlings N.D., Engel J.C., FrankLIN C., MCKerrow J.H. 1997: A primitive enzyme for a primitive cell: the protease required for excystation of Giardia. Cell 89: 437-444.

Wu Z., Nagano I., Takahashi Y., Maekawa Y. 2016: Practical methods for collecting Trichinella parasites and their excretory-secretory products. Parasitol. Int. 65: 591-595.

Wu Z., Tang Z., Shang M., Zhao L., Zhou L., Kong X., Lin Z., Sun H., Chen T., Xu J., Li X., Huang Y., Yu X. 2017: Comparative analysis of immune effects in mice model: Clonorchis sinensis cysteine protease generated from recombinant Escherichia coli and Bacillus subtilis spores. Parasitol. Res. 116: 1811-1822.

Yang J., Pan W., Sun X.M., Zhao X., Yuan G., Sun Q., Huang J., ZHU X. 2015: Immunoproteomic profile of Trichinella spiralis adult worm proteins recognised by early infection serum. Parasit. Vectors 8: 20.

Yang Y., Zhang Z., Yang J., Chen X., Cui S., Zhu X. 2010: Oral vaccination with Ts 87 DNA vaccine delivered by attenuated Salmonella typhimurium elicits a protective immune response against Trichinella spiralis larval challenge. Vaccine 28: 2735-2742.

Zhang Y.L., Wang Z.Q., Li L.G., CUi J. 2013: Molecular characterisation of Trichinella spiralis aminopeptidase and its potential as a novel vaccine candidate antigen against trichinellosis in BALB/c mice. Parasit. Vectors 6: 246.

Cite this article as: Song Y.Y, Wang L.A., Ren H.N., Qi X., Sun G.G, Liu R.D., Jiang P., Zhang X., Cui J, Wang Z.O. 2018: Cloning, expression and characterisation of a cysteine protease from Trichinella spiralis. Folia Parasitol. 65: 007 